\title{
Mercosul, competitividade e educação
}

\section{NELSON PILETTI e WALTER PRAXEDES}

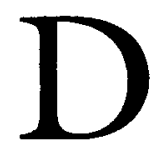

ESDE JANEIRO DE 1995 estão funcionando uma Zona de Livre Comércio e uma União Aduaneira, apontando ambas para a conformação de um território econômico comum entre Argentina, Brasil, Paraguai, e Uruguai. A livre circulação de bens, serviços e capitais entre os países envolvidos transformou-se em estratégia para a busca de inserção competitiva em um cenário internacional caracterizado pela globalização dos circuitos produtivos e pela consolidação dos blocos regionais de comércio, em um contexto histórico pós-Guerra Fria marcado pelo influxo das novas tecnologias de informação e das novas organizações enxutas e flexíveis.

O Mercado Comum do Sul, Mercosul, alia os quatro países membros na tentativa de que a liberalização do comércio intrabloco, simultaneamente à “adoção de acordos setoriais, com fim de otimizar a utilização e mobilidade de fatores de produção e alcançar escalas operativas eficientes " - como expressa $O$ artigo $5^{\circ}$ do Tratado de Assunção - credencie os parceiros para competir com eficácia em terceiros mercados.

Confirma-se, assim, na América Latina, a tendência de os Estados nacionais internacionalizarem suas estruturas internas e suas funções para a adaptação das economias nacionais às exigências do sistema liberalizado de comércio e investimento em escala mundial.

$\mathrm{Na}$ área educacional, como lhe é característico, a teoria do capital humano identifica as possibilidades de crescimento sócio-econômico, no atual contexto internacional, à capacitação tecnológica que, por sua vez, depende de educação e formação profissional adequadas.

De acordo com o documento básico do seminário sobre Reforma Educativa, promovido pelo Banco Interamericano de Desenvolvimento (BID) em Buenos Aires no dia 21 de março de 1996, de autoria de Martin Carnoy (Universidade de Stanford) e Claudio de Moura Castro (BID), “de resultas de las enormes transformaciones de la economía mundial en los pasados 20 años, la calidad de los sistemas educacionales ba pasado a ser un factor mucho más importante para la prosperidad económica de las naciones”. 
Neste fim de século e por esses caminhos, a educação volta a ocupar lugar central nas estratégias governamentais e empresariais, por constituir um fator fundamental no processo de qualificação de recursos humanos para a produção e o consumo baseados em altas tecnologias, adequadas ao nível da competitividade internacional. É nesse sentido que analisamos e interpretamos o tratamento que a educação formal vem recebendo por parte dos governos e dos chamados agentes econômicos do Mercosul. O que procuramos explicitar é a direção apontada pelas mudanças que vêm sendo propostas para a educação, considerada como um fator que pode alavancar ou dificultar o incremento da competitividade internacional das empresas da sub-região. Apesar de não compartilharmos com essa perspectiva educacional, julgamos necessário explicitá-la por considerar que significativa parte dos estudos acadêmicos existentes sobre a educação nos países do Mercosul privilegia uma abordagem prescritiva e pouco provável de tornarse realidade, além de informar muito pouco sobre a lógica de atuação dos centros decisórios e grupos de pressão que realmente traçam os rumos do atual processo integracionista.

\section{Competitividade e educação}

O Mercosul foi concebido com o objetivo prioritário de possibilitar uma adequada inserção internacional para os países. Para tanto, considerase imprescindível o aprimoramento do grau de competitividade de suas empresas.

O que se entende por competitividade? Em muitos autores, tal conceito apresenta-se difuso em um conjunto de variáveis, tornando dificil a sua quantificação para avaliar o desempenho econômico dos países. Não é o caso de Pereira (1995), em cuja definição, razoavelmente compartilhada, afirma que "um país é tanto mais competitivo quanto maior for o número de setores em que a participação nas importações da OCDE está crescendo".

Se, por um lado, tal definição parece um tanto restrita, por outro, possibilita a formulação de um indicador de desempenho que enfatize $o$ grau de adaptabilidade dos países e de seus setores exportadores às mudanças da estrutura de demanda dos países desenvolvidos.

Os setores econômicos exportadores, e mesmo aqueles voltados para os mercados internos do Mercosul, atentos à acirrada concorrência que a abertura comercial impõe, esforçam-se no sentido de incrementar a produtividade de suas unidades de produção, reduzindo custos, aumentando a qualidade e desenvolvendo novos processos de produção e serviços, mais eficazes e mais atraentes para os consumidores dos mercados almejados. 
Para alcançar tais objetivos torna-se imprescindível utilizar equipamentos tecnologicamente sofisticados nas indústrias e nos serviços, mas não é menos fundamental introduzir "inovações organizacionais e de gestão baseadas na cooperação, autodisciplina, auto-aperfeiçoamento contínuo e na coordenação horizontal", podendo-se mencionar o advento de um "novo paradigma tecnológico/organizacional que vem gerando novos conjuntos de produtos, serviços, sistemas e indústrias" (Nakano, 1994: 10-11).

O quadro a seguir resume as diferenças entre o velho o o novo paradigma tecnológico/organizacional, este mais adequado aos requerimentos da competição global.

Quadro 1- Mudanças no paradigma tecnológico

\begin{tabular}{|ll|}
\hline Velho Paradigma & Novo Paradigma \\
\hline Intensivo em energia & $\begin{array}{l}\text { Intensivo em informação } \\
\text { e conhecimento }\end{array}$ \\
$\begin{array}{l}\text { Grandes unidades de produção } \\
\text { e número de trabalhadores }\end{array}$ & $\begin{array}{l}\text { Redução no tamanho da produção } \\
\text { e número de trabalhadores }\end{array}$ \\
$\begin{array}{l}\text { Produto homogêneo de uma } \\
\text { unidade de produção }\end{array}$ & Diversidade de produtos \\
$\begin{array}{l}\text { Padronização } \\
\text { Mix estável de produtos }\end{array}$ & $\begin{array}{l}\text { Customised (dirigida ao cliente) } \\
\text { Plantas e equipamentos } \\
\text { especializados }\end{array}$ \\
$\begin{array}{l}\text { Automação } \\
\text { Habilidades especializadas }\end{array}$ & Sistema de produção flexível \\
\end{tabular}

Fonte: Nakano, 1994: 11.

Entretanto, o conceito de competitividade extrapola as dimensões estritamente empresariais, mesmo se aceitarmos a demanda dos países mais desenvolvidos economicamente como critério para a reestruturação das sociedades latino-americanas, o que é muito questionável. Como afirmou Batista (1994: 79), "por mais eficiente que seja uma empresa, sua capacidade 
de competição, no país como no exterior, dependerá, em última análise, do entorno nacional em que opera, da capacidade sistêmica de competição do país em termos de estabilidade macroeconômica, política cambial, infraestrutura de comunicações, de transportes, de educação, sistema financeiro e nível de qualificação de mão-de-obra". Ou seja, para que os agentes econômicos se adaptem às mudanças no paradigma tecnológico/organizacional, no sentido de atenderem à exigência de competitividade da economia global, é preciso que o país onde operam conte com determinadas pré-condições políticas, econômicas e sociais.

Uma dessas pré-condições é a subordinação dos sistemas educacionais aos requerimentos de competitividade das empresas. Com o aparecimento de um novo paradigma tecnológico/organizacional, as características da qualificação dos trabalhadores passam a ser a capacidade de manipular mentalmente modelos; a capacidade de pensar conceitualmente por meio de raciocínios abstratos; a compreensão do processo produtivo como um todo; a capacidade de avaliar tendências; a capacidade de avaliar os limites e significados dos dados estatísticos; a precisão nas formas de comunicação verbal, oral e visual; a responsabilidade; a capacidade de desempenhar múltiplos papéis na produção e de adaptação rápida a novas gerações de ferramentas e equipamentos (Paiva: 1993). De acordo com um estudo da Harvard Business School, também citado por Paiva, "os imperativos de qualidade e produtividade que estão no cerne da nova concorrência industrial são impossíveis de satisfazer sem a participação ativa, leal e engajada de uma mão-de-obra bem formada e em aperfeiçoamento constante".

É nesse sentido que o documento Educação e Conbecimento: cixo da transformaģão produtiva com eqüidade, elaborado pela Comissão Econômica para a América Latina (Cepal), enfatiza a necessidade de complementaridade entre as estratégias educacionais para a promoção da cidadania e para a eqüidade, com uma nova inspiração paradigmática no conceito de competitividade.

$\mathrm{Na}$ análise apresentada, a Cepal considera que os sistemas educativos latino-americanos têm funcionado antes como segmentadores que integradores, tornando-se afastados "cada vez mais das necessidades produtivas dos países", e cada vez mais inadequados frente às demandas do mercado de trabalho. Para que esta situação se transforme, "é necessário deixar de encarar a educação, a capacitação e a investigação como compartimentos estanques, e avançar em direção a um enfoque sistêmico, que integre estas três dimensões entre si e todas elas com o sistema produtivo", uma vez que "a incorporação e difusão de progresso técnico é o fator fundamental 
para que a região desenvolva uma competitividade autêntica que lhe permita se inserir com êxito na economia mundial" (Cepal, 1993: 7-9).

Para tanto, ao lado do financiamento estatal da educação, recomendase a "mobilização de diversas fontes de financiamento, que incluam de maneira crescente os recursos privados", bem como o estabelecimento de uma "nova relação entre educação, capacitação e empresa, na qual esta última assuma a liderança na formação de recursos humanos", com a realização de "um esforço conjunto de universidades, empresas e governo para incorporar a competitividade ao conhecimento" (Cepal, 1993: 9-10) .

Muito semelhante é o posicionamento de um outro organismo internacional, o Banco Mundial, que tem defendido propostas favoráveis à privatização da educação também em razão de que "a necessidade de aumentar a competitividade econômica está produzindo uma mudança de enfoque muito significativa, referente à capacitação dos recursos humanos e à produção de conhecimentos, que colocam novamente a educação na agenda de prioridades das inversões privadas" (Tedesco, 1991: 24).

Para o Banco Mundial, uma política de privatização possibilitará o controle comunitário sobre o pessoal e a direção das escolas, levando os pais a influenciarem no incremento da qualidade dos serviços prestados, e a superação das limitações impostas pela restrição orçamentária do setor público.

\section{A educação no Mercosul}

O Mercosul, organizado com vistas a incrementar a competitividade dos setores econômicos mais dinâmicos dos países envolvidos, está oportunizando a reintrodução da educação enquanto fator importante para as estratégias empresariais, uma vez que a qualidade de ensino nos países da região "é cada vez mais percebida como algo inferior, incompatível com qualquer pretensão a competir em iguais condições num mercado mundial altamente dependente de ciência e de tecnologia de ponta"(Scuro Neto: $74)$.

No quadro 2 compara-se alguns indicadores populacionais dos países do Mercosul; no quadro 3 é apresentado o nível de instrução da PEA nos quatro países e demonstrada a deficiência educacional já mencionada, apontando a precariedade da educação básica no Brasil e no Paraguai, a situação menos pior na Argentina e a superioridade na quantidade de anos de escolarização da PEA uruguaia. 
Quadro 2 - Indicadores demográficos do Mercosul

\begin{tabular}{|lcccc|}
\hline Indicadores & Argentina & Brasil & Paraguai & Uruguai \\
\hline População (milhões) & 33,1 & 154 & 4,6 & 3,1 \\
Densidade (hab./km²) & 12,1 & 17,7 & 11,3 & 17,6 \\
& & & & \\
População por idade & & & & \\
0 a 14 (\%) & 29,6 & 34,7 & 40,6 & 25,8 \\
I5 a 59 (\%) & 56,9 & 57,8 & 54,0 & 57,7 \\
mais de 60(\%) & 13,2 & 7,3 & 5,4 & 16,5 \\
& & & & \\
Pop. urbana (\%) & 87,0 & 77,0 & 51,0 & 89,0 \\
Crescimento (\% anual) & 1,2 & 1,9 & 2,7 & 0,6 \\
$\begin{array}{l}\text { Natalidade (por mil) } \\
\text { Mortalidade (por mil) }\end{array}$ & 20,0 & 25,3 & 33,0 & 17,6 \\
$\begin{array}{l}\text { Mortalidade infantil } \\
\text { (por mil) }\end{array}$ & 9,0 & 6,6 & 6,0 & 9,8 \\
$\begin{array}{l}\text { Fertilidade } \\
\text { (n⿳⺈ de filhos por mulher) }\end{array}$ & 2,7 & 2,7 & 4,3 & 2,3 \\
$\begin{array}{l}\text { Expectativa de vida } \\
\text { ao nascer homens (anos) }\end{array}$ & 68,0 & 62,1 & 65,1 & 68,9 \\
$\begin{array}{l}\text { Expectativa de vida } \\
\text { ao nascer mulheres (anos) }\end{array}$ & 74,0 & 68,9 & 69,5 & 75,3 \\
$\begin{array}{l}\text { População economicamente } \\
\text { ativa (em milhões) }\end{array}$ & 12,6 & 67,8 & 1,7 & 1,4 \\
& & 68,0 & 47,0 & 20,4 \\
\hline
\end{tabular}

Fontes: Indicadores de Desenvolvimento do Cone Sul (Cepal). Almanaque Abril, São Paulo, 1995. Informe Sobre o Desenvolvimento Mundial - Banco Mundial, 1992. Gazeta Mercantil, 2.1.95. Jornal Folha de S. Paulo, 30.7.95. Os números indicam os últimos dados disponíveis apenas para efeito comparativo. 
Quadro 3 - Nível de Instrução da PEA (\%)

\begin{tabular}{|lcccc|}
\hline Anos de estudo & Argentina & Brasil & Paraguai & Uruguai \\
\hline Nenhum ano de estudo & - & 27,1 & 7,4 & 2,8 \\
1 a 3 anos de estudo & 29,4 & 24,7 & 66,8 & 20,2 \\
4 a 6 anos de estudo & 48,4 & 28,1 & - & 28,5 \\
7 a 9 anos de estudo & 16,9 & 10,1 & 21,1 & 22,3 \\
10 a 12 anos de estudo & - & 6,8 & - & 4,2 \\
13 e mais anos de estudo & 5,3 & 3,1 & 4,7 & 21,3 \\
\hline
\end{tabular}

Fonte: Indicadores de Desenvolvimento do Cone Sul (Cepal). Os números se referem ao ano base de 1980 .

Para governos e empresários do Mercosul, que visam ao sucesso na estratégia de inserção na economia mundial, as metas buscadas para a área educacional devem se subordinar a esse fim. Daí a importância da implementação de sistemas de avaliação do ensino mediante o desenvolvimento de indicadores educacionais confiáveis internacionalmente e que evidenciem as características da qualificação da força-de-trabalho, possibilitando a busca de padrões educacionais de qualidade, funcionais e compatíveis quanto à competitividade internacional.

Em razão do baixo nível educacional dos trabalhadores, até mesmo os programas internos das empresas para treinamento acabam dificultados. Em um estudo de Humphrey (1994) sobre a gestão de mão-de-obra e os sistemas de produção no Terceiro Mundo, fica evidenciado o déficit de educação básica existente no estado de São Paulo, principal região de concentração industrial do Mercosul, onde a maioria dos empregados jovens na indústria continua não tendo a educação primária completa.

Para fazer frente a esta situação, algumas companhias oferecem cursos de alfabetização, matemática e estatística elementar, atividades de controle de qualidade, além de cursos de primeiro e segundo grau para superar as deficiências de leitura, redação, raciocínio e habilidades de comunicação dos trabalhadores (Humphrey, 1994: 127-128). 
No mesmo estudo, Humphrey explica que a implantação bem sucedida dos sistemas Just in Time e Total Quality Control pressupõe, pelo menos, trabalhadores com alfabetização e educação primária, identificados como essenciais para uma estratégia exitosa de exportação da produção, além de "trabalhadores com educação em nível secundário para a integração extensiva de tarefas de qualidade e manutenção nos trabalhos de produção, e para a melhor utilização de círculos de Quality Control e outras atividades de melhoria" (Humphrey, 1994: 141).

A título de exemplo, vejamos o caso da holding Autolatina, que em 1993 e 1994 esteve no topo da lista das empresas instaladas no Brasil que mais exportaram para o Mercosul. Para fazer frente ao problema da baixa escolarização formal dos seus trabalhadores, a empresa investiu US $\$ 48,5$ milhões em programas de educação e treinamento no decorrer de quatro anos. Em 1990, 63\% dos seus trabalhadores horistas não contavam com o primeiro grau completo. Ao final desses quatro anos foram diplomados três mil empregados no primeiro grau. Paralelamente ao desenvolvimento dos cursos, a produtividade na Autolatina saltou de oito veículos por trabalhador, em 1990, para 15 por um, em 1994, quando o total de empregados com escolarização inferior ao primeiro grau caiu para $45 \%$ (Veja, 19.10.94).

Apesar de altamente expressivos, tais dados não devem corroborar a conclusão pura e simples pela existência de causa e efeito direta entre a maior qualificação dos trabalhadores e o incremento da produtividade. Embora não seja nosso objetivo nos aprofundar nesta questão, não podemos deixar de registrar a precariedade dos indicadores de produtividade, que não é medida apenas como produção física final, isto é, pelo número de veículos por trabalhador. No mesmo período, na Autolatina, também houve a intensificação da terceirização na produção e o aumento do conteúdo importado dos carros, fatos que certamente também influíram no aumento do número de veículos produzidos por empregado.

Entretanto, além da exigência de maior qualificação dos trabalhadores, há outro aspecto a considerar no caso da Autolatina: a redução relativa e absoluta do número de empregados entre os anos de 1989 e 1994. Em 1989, com 55 mil empregados, a Autolatina produzia em média 41 mil veículos por mês; em outubro de 1994, a produção média mensal saltou para 50 mil automóveis e o número de empregados caiu para 47 mil, quando poderia ter chegado a 67 mil empregados, se o nível de produtividade de 1989 tivesse permanecido. Esses dados comprovam empiricamente a tendência de incremento na produtividade das indústrias em detrimento do nível de emprego, tendência esta que se manifesta no Mercosul por meio 
das expressivas taxas de desemprego urbano verificadas principalmente na Argentina, que atingiu em maio de 1995 o índice de $18,6 \%$, e no Uruguai, onde este índice chegou a 10,4\% em dezembro de 1994 . No Brasil, a despeito da taxa de desemprego menos expressiva que na Argentina e no Uruguai, chegando em julho de 1995 a 4,83\%, em outubro de 1994 a indústria paulista produzia a mesma quantidade de cinco anos antes, mas empregando $25 \%$ de trabalhadores a menos, segundo a Federação das Indústrias do Estado de São Paulo. Confirma-se, assim, a previsão pessimista feita por Almeida (1993: 22-23), segundo a qual o processo de integração do Mercosul não se fará "sem custos sociais e econômicos relativos, que são os derivados dos esforços de adaptação e de reconversão que devem empreender os operadores econômicos confrontados com novas condições de concorrência". Em 1993 Almeida já vislumbrava "a possibilidade de que trabalhadores menos especializados ou empregados em setores de baixa eficiência econômica relativa venham a ser deslocados para ocupações em outras áreas ou possam mesmo engrossar as fileiras daquilo que Marx chamava de 'exército industrial de reserva" ".

\section{A integração educativa}

Atento à centralidade que a educação passa a ter para a competitividade de países e setores econômicos no comércio mundial, o Conselho de Mercado Comum (CMC), em sua segunda reunião, ocorrida em Las Leñas em 26 de julho de 1992, aprovou o Plano Trienal para a integração educativa e a formação de uma comissão conjunta de ministros das áreas do Trabalho, Justiça e Educação, com a finalidade de propor medidas práticas e acompanhar a implementação das políticas educativas entre países membros do Mercosul, visando prioritariamente "a formação da consciência cidadã favorável à integração; a capacitação de recursos humanos para contribuir para o desenvolvimento da economia, e a harmonização dos sistemas educativos dos países Argentina, Brasil, Uruguai e Paraguai" (Morosini, 1994: 28).

Na mesma linha do documento Educação e Conbecimento: eixo de transformação produtiva com eqüidade, da Cepal, já discutido, o Plano Trienal para o Setor Educacional do Mercosul tem como um dos pressupostos principais o fortalecimento dos vínculos entre o setor educativo e o setor produtivo, na tentativa de adequar-se às exigências dos processos de reconversão competitiva com vistas a melhor posicionar os setores econômicos na concorrência internacional. Em outros termos, na medida que a integração entre os quatro países busca ampliar o espaço operacional das empresas instaladas na sub-região, a integração educativa vislumbrada 
pelos negociadores oficiais acaba obedecendo à lógica das demandas de mercado.

Mesmo nesta perspectiva, considerando-se que na área educacional "entram componentes dificeis de equalizar como língua, tradição cultural e as questões referentes a currículos educacionais e condições para o exercício profissional", na visão do ex-Ministro da Educação José Goldemberg ( $O$ Estado de S. Paulo, 1.1.95), "a integração econômica de um grupo de países é muito mais fácil de promover do que a sua integração educacional". A equalização de currículos e de concepções educacionais distintas vigentes nos países do Mercosul não é tarefa fácil.

Um exemplo: curso de graduação para o exercício da profissão de contador constitui uma amostra das dificuldades a serem enfrentadas. Enquanto no Brasil e no Paraguai o curso de graduação em Ciências Contábeis é autônomo em relação aos cursos de Ciências Econômicas, Atuariais e de Administração de Empresas, e destina-se à formação de bacharéis com titulação própria, que passam a ser denominados contadores após o registro no Conselho Regional de Contabilidade, na Argentina e no Uruguai o título de contador é considerado como simples degrau para o título final de economista. Em termos práticos, "a legislação brasileira concede aos profissionais de contabilidade, a par da sua diferenciação dos economistas e administradores, uma gama de prerrogativas inexistentes nos outros países do Mercosul" (Koliver, 1993: 8), a exemplo da obrigatoriedade da assinatura de um contabilista credenciado no Conselho Regional de Contabilidade em qualquer demonstração contábil.

Outras dificuldades concernentes à integração educativa resultam da dimensão das disparidades e desproporções existentes entre os sistemas educacionais dos países do Mercosul, como pode se depreender dos indicadores apresentados no quadro 4. 
Quadro 4 - Indicadores educacionais do Mercosul

\begin{tabular}{|lcccc}
\hline Indicadores & Argentina & Brasil & Paraguai & Uruguai \\
\hline $\begin{array}{l}\text { Analfabetismo (\%) } \\
\text { Alunos cursando o 1 }\end{array}$ & 4,7 & 18,9 & 9,9 & 3,8 \\
${\text { e } 2^{\circ} \text { Graus (em milhares) }}^{\text {Professores de 1 }}$ & 6800 & 34000 & 890 & 612 \\
$\begin{array}{l}\text { e } 2^{\circ} \text { Graus (em milhares) } \\
\text { Alunos de escola primária em escola } \\
\text { privadas (em \% de 1985) }\end{array}$ & 512 & 1514 & 50.8 & 33 \\
$\begin{array}{l}\text { Alunos cursando o ensino } \\
\text { superior (em milhares) }\end{array}$ & 18,6 & 12,1 & 17,7 & 15,4 \\
$\begin{array}{l}\text { Professores no ensino } \\
\text { superior (em milhares) }\end{array}$ & 903 & 1594 & 32,8 & 91,5 \\
$\begin{array}{l}\text { Indivíduos na faixa de 18 a 23 anos } \\
\text { na educação superior (\%) } \\
\text { Gastos em educação }\end{array}$ & 41 & 125,4 & 2,7 & 5,6 \\
em percentual do PIB & 4,2 & 2,9 & 1,6 & 2,3 \\
$\begin{array}{l}\text { Gastos em educação } \\
\text { em percentual do orçamento nacional }\end{array}$ & 22,6 & 16,9 & 16,7 & 9,3 \\
\hline
\end{tabular}

Fontes: Indicadores de Desenvolvimento do Cone Sul (Cepal); Tedesco, 1991; Morosini, 1994; Informe sobre o Desenvolvimento Mundial, Banco Mundial, 1992; Abril Cultural, 1995.

Considerando as mencionadas dificuldades, além de outras certamente existentes, Goldemberg sugere, como ponto de partida para a reorganização dos sistemas educacionais dos países do Mercosul, a uniformização das condições para o exercício profissional, medida que induziria ao reconhecimento mútuo dos diplomas atribuídos pelos sistemas de ensino de cada país, o que, por sua vez, só ocorreria com o atendimento à pré-condição da uniformização ou, ao menos, da compatibilização dos currículos das diferentes escolas.

Como a livre circulação dos trabalhadores, a exemplo do que ocorre atualmente na União Européia, está ainda num horizonte muito distante 
para o Mercosul, na prática a integração educativa está se iniciando por áreas menos complicadas e que não despertam a oposição das corporações profissionais existentes. Em agosto de 1994, o Conselho de Mercado Comum aprovou o Protocolo sobre integração educativa e reconhecimento de certificados, títulos e estudos de nível primário e médio não técnico, estabelecendo o reconhecimento dos certificados em cada um dos países membros, nas condições estabelecidas pelo país de origem, para os alunos ou ex-alunos das instituições educacionais reconhecidas oficialmente, em razão dos quatro governos estarem "conscientes de que a educação é um fator fundamental no cenário dos processos de integração regional ... e prevendo que os sistemas educativos devem dar resposta aos desafios suscitados pelas transformações produtivas, pelos avanços científicos e técnicos ...".

Ao longo do atual processo de integração, iniciado com os protocolos do Programa de Integração e Cooperação Econômica Argentina-Brasil (PICE), firmados em 1986, ainda nos mandatos presidenciais de Raul Alfonsin, na Argentina, e José Sarney, no Brasil, e que toma contornos mais nítidos e acelerados a partir do Tratado de Assunção de 1991, vários foram os acordos firmados no intuito de adequar os sistemas educativos dos Estados-partes às exigências econômicas e sociais vislumbradas pelos negociadores oficiais. Mas, sem dúvida, o Protocolo sobre o reconhecimento dos certificados e estudos em níveis primário e médio não-técnico afigurase como o acordo de maior alcance para a área educacional, por permitir o reconhecimento e o prosseguimento dos estudos nos quatro países, de acordo com o quadro reproduzido na próxima página.

Para garantir a implementação deste Protocolo o Conselho de Mercado Comum estabeleceu que a reunião de ministros da Educação do Mercosul “propenderá à incorporação de conteúdos curriculares mínimos de história e geografia de cada um dos Estados-partes" e criou uma Comissão Regional Técnica, integrada por delegações dos Ministérios da Educação de cada país, que poderá se reunir sempre que houver questões prementes para os rumos da integração educativa.

Quanto aos reflexos do processo integracionista no ensino superior dos países do Mercosul, os programas em fase embrionária de implementação seguem a orientação geral apresentada no decorrer deste artigo, de acordo com o Programa de Capacitação de recursos humanos para contribuir para o desenvolvimento, proposto visando à formação de recursos humanos de alto nivel, e que conta do lado brasileiro com o engajamento da Capes em sua condução. Tudo indica que nas próximas reuniões oficiais entre os ministros da Educação o tema da integração universitária no âmbito do Mercosul será priorizado, uma vez que segundo Landinelli (1994: 225), os sistemas 
universitários são considerados estratégicos para o desenvolvimento econômico dos países da sub-região, pois "se exigirá cada vez más personal competente en materia de comunicación, de idiomas, de gestión y de organización y se observará, por ende, una mayor demanda de aquellos que posean un nipel de educación superior y competencias múltiples, tanto por parte de la industria como de los servicios". Para esta perspectiva educacional, a integração entre os parceiros do Mercosul dificilmente avançará sem a melhora na eficiência da educação superior e a modernização dos sistemas educativos da sub-região.

Quadro 5 - Comparação entre anos de escolaridade no Mercosul

\begin{tabular}{|llll|}
\hline Argentina & Brasil & Paraguai & Uruguai \\
\hline $1^{\circ}$ Primário & $1^{\circ}$ Fundamental & $1^{\circ}$ Primário & $1^{\circ}$ Primário \\
$2^{\circ}$ Primário & $2^{\circ}$ Fundamental & $2^{\circ}$ Primário & $2^{\circ}$ Primário \\
$3^{\circ}$ Primário & $3^{\circ}$ Fundamental & $3^{\circ}$ Primário & $3^{\circ}$ Primário \\
$4^{\circ}$ Primário & $4^{\circ}$ Fundamental & $4^{\circ}$ Primário & $4^{\circ}$ Primário \\
$5^{\circ}$ Primário & $5^{\circ}$ Fundamental & $5^{\circ}$ Primário & $5^{\circ}$ Primário \\
$6^{\circ}$ Primário & $6^{\circ}$ Fundamental & $6^{\circ}$ Primário & $6^{\circ}$ Primário \\
$7^{\circ}$ Primário & $7^{\circ}$ Fundamental & $1^{\circ}$ Básico Médio & $1^{\circ}$ Básico Secundário \\
$1^{\circ}$ Secundário $8^{\circ}$ Fundamental & $2^{\circ}$ Básico Médio & $2^{\circ}$ Básico Secundário \\
$2^{\circ}$ Secundário $1^{\circ}$ Médio & $3^{\circ}$ Básico Médio & $3^{\circ}$ Básico Secundário \\
$3^{\circ}$ Secundário $2^{\circ}$ Médio & $4^{\circ}$ Básico Médio & $4^{\circ}$ Básico Secundário \\
\hline
\end{tabular}

Fonte: Gazeta Mercantil, 8 ago. 1994.

\section{Conclusão}

Procuramos evidenciar que o tratamento dispensado às questões educacionais pelos representantes dos governos que implementam o processo integracionista segue a tendência contemporânea de revigoramento da já antiga Teoria do capital bumano, reintegrando no debate atual uma abordagem economicista e de sentido liberalizante. Vislumbra-se dessa forma a reestruturação da educação dos países que compõem o Mercosul como 
mais um setor sócio-econômico que deve ser racionalizado e modernizado, de modo a possibilitar o incremento da competitividade internacional das empresas instaladas na região.

Entretanto, mesmo nessa perspectiva economicista, as iniciativas adotadas no campo educacional revestem-se de acentuada fragilidade, na medida que priorizam aspectos formais e credencialistas, dispensando pouca ou nenhuma atenção ao próprio conteúdo de educação.

Em face das limitações da perspectiva que condiciona a legitimidade social dos sistemas educacionais à sua rentabilidade econômica para os grupos empresariais, bem como da fragilidade das primeiras iniciativas empreendidas, entendemos ser necessário que novas alternativas passem a hegemonizar o debate e as práticas educacionais no âmbito do processo de integração entre os países do Mercosul.

\section{Referências bibliográficas}

ALMEIDA, Paulo R. O Mercosul no contexto regional e internacional. São Paulo, Aduaneiras, 1993.

BATISTA, Paulo N. O Mercosul e os interesses do Brasil. Estudos Apançados, v. 8, n. 21, p. 79-95, 1994.

CARNOY, Martin \& MOURA CASTRO, Cláudio de. ¿Qué rumbo debe tomar el mejoramento de la educación en América Latina? Documentos de antecedentes para el Banco Interamericano de Desarrolo. Seminário sobre reforma educativa. Buenos Aires (Argentina), 21 de março de 1996.

CEPAL. Educaf̧ão e conbecimento: eixo da transformação produtiva com eqüidade. Brasília, Ministério da Educação, 1993.

DEMO, Pedro. Desafios modernos da educação. Petrópolis, Vozes, 1993.

Gazeta Mercantil, 8 ago. 1994.

GOLDEMBERG, J. O Mercosul e a educação. O Estado de S. Paulo, 1 jan. 1995.

HUMPHREY, John. A gestão de mão-de-obra e os sistemas de produção no Terceiro Mundo. Estudos Avançados, v. 8, n. 21, p. 119-46, 1994.

IANNI, Otávio. A sociedade global. Rio de Janeiro, Civilização Brasileira, 1992.

INDICADORES Econômicos Internacionais. Folha de S. Paulo, 27 ago. 1995.

KOLIVER, O. O exercício profissional no âmbito dos países do Mercosul. Revista do Conselho Regional de Contabilidade do Rio Grande do Sul, n. 75, 1993. 
LANDINELLI, J. La función pública de la universidad uruguaya. In: Morosini, M. C. (org.). Universidade no Mercosul. São Paulo, Cortez, 1994.

MELLO, G. N. Políticas públicas de educação. Instituto de Estudos Avançados, Coleção Documentos, v. 1, 1991.

MOROSINI, M.C. Universidade e integração no Mercosul: condicionantes e desafios . In: Morosini, M.C. (org.). Universidade no Mercosul, São Paulo, Cortez, 1994.

NAKANO, Yoshiaki. Globalização, competitividade e novas regras de comércio mundial. Revista de Economia Politica, v. 14, n. 4, out./dez. 1994.

PAIVA, V. Novo paradigma de desenvolvimento: educação, cidadania e trabalho. Revista de Ciência da Educação, Educação e Sociedade, ano XIV, n. 45, ago. 1993, Campinas, Cedes/Papirus, 1993.

PEREIRA, Lia V. Competitividade no Mercosul. Conjuntura Econômica. Rio de Janeiro, Fundação Getúlio Vargas, jun. 1995.

PILETTI, N. \& PRAXEDES, W. O Mercosul e a sociedade global. São Paulo, Ática, 1995.

SCURO Neto, Pedro. A formação de recursos humanos. São Paulo, Instituto de Estudos Avançados, Coleção Documentos, v. 20, 1991.

TEDESCO, Juan C. Alguns aspectos da privatização educativa na América Latina. Estudos Avançados, v. 5, n. 12, p. 23-44, 1991.

Nelson Piletti é professor da Faculdade de Educação da Universidade de São Paulo e co-autor de O Mercosul e a Sociedade Global (São Paulo, Ática, 1995).

Walter Praxedes é professor da Universidade Estadual de Maringá, Paraná e coautor de $O$ Mercosul e a Sociedade Global. 